\title{
Structural characterization of exopolysaccharide from Streptococcus thermophilus ASCC 1275
}

\author{
Aparna Padmanabhan (1) and Nagendra P. Shah* (1) \\ Food and Nutritional Science, School of Biological Sciences, The University of Hong Kong, Pokfulam Road, Hong Kong SAR, China
}

\begin{abstract}
In this study, we purified and characterized exopolysaccharide (EPS) produced by a high-EPS-producing dairy starter bacterium, Streptococcus thermophilus ASCC 1275. Crude EPS was extracted from S. thermophilus ASCC 1275 and partially purified using dialysis. Further purification and fractionation of exopolysaccharide was conducted using HPLC on a Superose 6 column (Cytiva/Global Life Sciences Solutions, Marlborough, MA). Glycosyl composition analysis, linkage analysis along with 1-dimensional and 2-dimensional nuclear magnetic resonance spectroscopy were performed to deduce the structure of EPS. Three fractions (F) obtained from gel permeation chromatography were termed F1 (2.6\%), F2 (45.8\%), and F3 (51.6\%) with average molecular weights of approximately 511, 40 , and $5 \mathrm{kDa}$, respectively. Monosaccharide composition analysis revealed the dominance of glucose, galactose, and mannose in all 3 fractions. Major linkages observed in F3 were terminal galactopyranosyl (t-Gal), 3-linked glucopyranosyl (3-Glc), 3-linked galactofuranosyl (3-Galf), and 3,6-linked glucopyranosyl (3,6Glc) and major linkages present in F2 were 4-Glc (48 mol\%), followed by terminal mannopyranosyl (t-Man), 2- + 3-linked mannopyranosyl (2-Man+3-Man), and 2,6-linked mannopyranosyl (2,6-Man; total $\sim 28 \mathrm{~mol} \%$ ). The 1-dimensional and 2-dimensional nuclear magnetic resonance spectroscopy revealed that F2 comprised mannans linked by $(1 \rightarrow 2)$ linkages and F3 consisted of linear chains of $\alpha$-D-glucopyranosyl ( $\alpha$-D-Glc $p), \beta$-Dglucopyranosyl ( $\beta$-D-Glc $p$ ), and $\beta$-D-galactofuranosyl $(\beta$-D-Galf) connected by $(1 \rightarrow 3)$ linkages; branching was through $(1 \rightarrow 6)$ linkage in F3. A possible structure of EPS in F2 and F3 was proposed.
\end{abstract}

Received August 12, 2019.

Accepted March 16, 2020.

*Corresponding author: npshah@hku.hk
Key words: exopolysaccharide, structure, glycosyl linkage, nuclear magnetic resonance (NMR)

\section{INTRODUCTION}

Exopolysaccharides (EPS) are long-chain polymers synthesized by microbes; EPS usually comprise repeating sugars or sugar derivatives arranged in linear or branched form. During growth, EPS is secreted into the external environment by microbes, distinguishing EPS from capsular polysaccharides, which are cell bound (Laws et al., 2001; Welman and Maddox, 2003). The EPS produced by lactic acid bacteria (LAB) or EPS-producing strains of LAB can be used directly in fermented dairy food production because of the generally regarded as safe (GRAS) status of LAB (Ai et al., 2016). Reports show that EPS-producing LAB improve the rheology, texture, and mouthfeel of various fermented products such as yogurt and cheese (de Vuyst et al., 2001; Purohit et al., 2009; Torino et al., 2015; Zannini et al., 2016; Zeidan et al., 2017). Moreover, EPS from LAB proved to have immunomodulatory (Patten and Laws, 2015; Laiño et al., 2016), antitumor (Moscovici, 2015) cholesterol-lowering (Khalil et al., 2018; Oleksy and Klewicka, 2018), antioxidant (Li et al., 2014; Patten and Laws, 2015), prebiotic (Torino et al., 2015; Korcz et al., 2018), and antibacterial (Li et al., 2014) effects, and have been found to increase the colonization of probiotic bacteria in the gastrointestinal tract (Welman and Maddox, 2003).

Based on the chemical composition, LAB-EPS are categorized into homopolysaccharides, containing the same monomer units, and heteropolysaccharides, containing multiple different monomer units. The diversity of LAB homopolysaccharides arises from differences in branching, glycosidic bonds, molecular weight, chain length, and polymer structure (Oleksy and Klewicka, 2018). $\alpha$-Glucans, $\beta$-glucans, fructans, and polygalactans are the different homopolysaccharides produced by LAB (Sanalibaba and Çakmak, 2016). Lactic acid bacteria also produce a variety of heteropolysaccharides with different structures and molecular masses and made of sugars such as glucose, galactose, rhamnose, 
and mannose and sugar derivatives such as glucuronic acid, $N$-acetylglucosamine, and $N$-acetylgalactosamine (Ibarburu et al., 2015). Mesophilic LAB (Lactobacillus rhamnosus, Lactococcus lactis ssp. lactis, Lactobacillus casei) and thermophilic LAB (Streptococcus thermophilus, Lactobacillus helveticus, Lactobacillus acidophilus, Lactobacillus delbrueckii ssp. bulgaricus) are considered the major producers of heteropolysaccharides (Bajpai et al., 2015). Molecular studies of various LAB suggest that the structural diversity of EPS cluster influences heteropolysaccharide structure (Dimopoulou et al., 2014; Ibarburu et al., 2015).

Streptococcus thermophilus is a conventional dairy starter culture used with $L$. delbrueckii ssp. bulgaricus for the preparation of yogurt. Streptococcus thermophilus ASCC 1275 is a dairy bacterium known to produce a high amount of EPS in milk compared with other known $S$. thermophilus strains. It produces both capsular and ropy EPS (Zisu and Shah, 2003). The complete genome sequencing of $S$. thermophilus ASCC 1275 was performed in our laboratory, and a novel EPS gene cluster was identified in its genome that included 2 chain-length-determining genes (Wu et al., 2015). Previous studies have shown enhanced texture-modifying properties in yogurt and mozzarella cheese due to the high amount of EPS from S. thermophilus ASCC 1275 (Bhaskaracharya and Shah, 2000; Zisu and Shah, 2005; Amatayakul et al., 2006a,b; Purwandari et al., 2007). It has also been shown that sulfated EPS have improved antioxidant, antibacterial, anti-inflammatory, and antiproliferative activities (Li and Shah, 2014, 2016, 2017). However, the exact structure of EPS produced by $S$. thermophilus ASCC 1275 has not yet been studied. Thus, the objective of this study was to elucidate the structure of EPS produced by $S$. thermophilus ASCC 1275 using glycosyl composition, glycosyl linkage, and nuclear magnetic resonance (NMR) analysis.

\section{MATERIALS AND METHODS}

\section{Inoculum Preparation and Fermentation}

Streptococcus thermophilus ASCC 1275 was procured from Australian Starter Culture Collection Research Centre (ASCRC; now Chr. Hansen Ltd., Werribee, Victoria, Australia). The bacterium was stored at $-80^{\circ} \mathrm{C}$ in M17 broth (BD Company, Franklin Lakes, NJ) mixed with glycerol $(20 \%, \mathrm{vol} / \mathrm{vol})$ in the same ratio. Working stocks were activated twice before fermentation using 1\% inoculum in M17 broth supplemented with $1 \%$ lactose at $37^{\circ} \mathrm{C}$ for $18 \mathrm{~h}$. Fermentation was carried out in a GLS 80 stirred reactor (Duran Group, Mainz,
Germany) containing $1 \mathrm{~L}$ of M17 broth inoculated with $1 \%$ of activated culture incubated at $37^{\circ} \mathrm{C}$ for $12 \mathrm{~h}$.

\section{Exopolysaccharide Extraction}

Exopolysaccharide was extracted from culture broth as reported by Li and Shah (2014). Briefly, 4\% trichloroacetic acid (TCA) was added to the fermentation broth $(1 \mathrm{~L})$ and stirred for $2 \mathrm{~h}$ at $25^{\circ} \mathrm{C}$. Cells and proteins were precipitated overnight at $4^{\circ} \mathrm{C}$ and removed by centrifugation at $12,000 \times g$ for $30 \mathrm{~min}$ at the same temperature. The supernatant collected was filtered (0.45- $\mu \mathrm{m}$ Acrocap filter; Pall Corporation, Port Washington, NY) and EPS was precipitated from it overnight using double the volume of ice-cold ethanol at $4^{\circ} \mathrm{C}$. The EPS was collected by centrifugation at $12,000 \times g$ for $20 \min \left(4^{\circ} \mathrm{C}\right)$, washed thrice with $50 \%$ ice-cold ethanol, dissolved in $10 \mathrm{~mL}$ of milli-Q water (Merck Millipore, Burlington, MA) and filtered using a $0.45-\mu \mathrm{m}$ Acrocap filter. This aqueous solution was then dialyzed against $2 \mathrm{~L}$ of milli-Q water through a cellulose dialysis membrane with a molecular weight (MW) cut-off of 12,000 for $3 \mathrm{~d}$ at $4^{\circ} \mathrm{C}$. Milli-Q water was changed twice a day. After dialysis, EPS was lyophilized and stored at $-20^{\circ} \mathrm{C}$ for further analysis. The phenol-sulfuric acid method was used to determine the EPS content with D-glucose as standard (DuBois et al., 1956).

\section{Size Exclusion Chromatography}

Purification and fractionation of EPS was performed by size exclusion chromatography (SEC) using a Superose 6 column $(10 \mathrm{~mm} \times 300 \mathrm{~mm}$; Cytiva/Global Life Sciences Solutions, Marlborough, MA). The EPS sample $(10 \mathrm{mg} / \mathrm{mL}$ in water $)$ was filtered using a 0.45 $\mu \mathrm{m}$ Acrocap filter and injected into the column. Ammonium acetate, $50 \mathrm{mM}, \mathrm{pH} 5.5$, was used to elute the fractions at a flow rate of $0.5 \mathrm{~mL} / \mathrm{min}$. Fractions were collected at every $1 \mathrm{~min}$. The EPS fractions were detected using refractive index detector (RID) coupled with HPLC. Dextran standards of MW 1, 10, 40, 67, 167 , and $511 \mathrm{kDa}$ were analyzed in parallel with the sample and a calibration curve was prepared.

\section{Glycosyl Composition Analysis}

Combined GC-MS was performed for glycosyl composition analysis of the per- $O$-trimethylsilyl (TMS) derivatives of monosaccharide methyl glycosides produced from the acid-hydrolyzed samples by acidic methanolysis as previously described by Santander et al. (2013). 
Aliquots of the SEC peaks collected were spiked with $20 \mu \mathrm{g}$ of inositol (internal standard) and heated with $1 \mathrm{M}$ methanolic $\mathrm{HCl}$ in a sealed screw-top glass test tube for $18 \mathrm{~h}$ at $80^{\circ} \mathrm{C}$. After cooling and removal of solvent under a stream of nitrogen, the samples were treated with a mixture of methanol, pyridine, and acetic anhydride for $30 \mathrm{~min}$. The solvents were evaporated and the sample was derivatized with Tri-Sil (Pierce/ ThermoFisher Scientific, Waltham, MA) at $80^{\circ} \mathrm{C}$ for 30 min. The GC/MS analysis of the resulting TMS methyl glycosides was performed on an Agilent 7890A GC (Agilent Technologies, Santa Clara, CA) interfaced to a 5975C MSD (Agilent Technologies), using a Supelco Equity-1 fused-silica capillary column $(30 \mathrm{~m} \times 0.25$ mm ID; Supelco, Sigma-Aldrich, St. Louis, MO).

\section{Enzymatic Digestion and Sample Preparation}

Contaminating proteins and RNA were removed from the fractions collected from SEC by enzymatic digestion followed by dialysis. Lyophilized EPS frac-

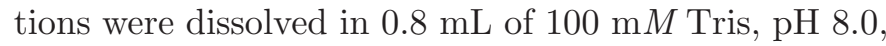
buffer into which $8 \mathrm{mM} \mathrm{MgCl} 2$ and $0.5 \mu \mathrm{L}$ of benzonase nuclease (Sigma-Aldrich) was added, and the mixture was incubated at $37^{\circ} \mathrm{C}$ for $24 \mathrm{~h}$ with agitation. Next, $5 \mathrm{mM} \mathrm{CaCl}{ }_{2}$ and $80 \mu \mathrm{g}$ of proteinase $\mathrm{K}$ was added, and the mixture was incubated at $37^{\circ} \mathrm{C}$ for $24 \mathrm{~h}$ with agitation. The digested sample was dialyzed in a $1-\mathrm{kDa}$ cut-off bag against deionized water. An aliquot ( $\sim 5$ $\mathrm{mg})$ was lyophilized, dissolved in $500 \mu \mathrm{L}$ of $\mathrm{D}_{2} \mathrm{O}(99.9 \%$ D, Sigma-Aldrich), lyophilized again, dissolved in 270 $\mu \mathrm{L}$ of $\mathrm{D}_{2} \mathrm{O}(99.96 \% \mathrm{D}$, CIL, Cambridge Isotope Laboratories, Tewksbury, MA) and transferred to a 5-mm Shigemi NMR tube (Sigma-Aldrich).

\section{Glycosyl Linkage Analysis}

For glycosyl linkage analysis, the lyophilized sample obtained after enzymatic digestion was permethylated, depolymerized, reduced, and acetylated. The resultant partially methylated alditol acetates were analyzed by GC-MS, as described by Heiss et al. (2009).

A portion of the NMR sample was lyophilized, giving $\sim 0.5 \mathrm{mg}$ of dry sample that was dissolved in dimethyl sulfoxide in the presence of $\mathrm{NaOH}$ and permethylated with methyl iodide (MeI). The permethylated material was hydrolyzed using $2 M$ trifluoroacetic acid (TFA, $2 \mathrm{~h}$ at $121^{\circ} \mathrm{C}$ ), and the resulting partially methylated monosaccharides were reduced with $\mathrm{NaBD}_{4}$ and acetylated with acetic anhydride and TFA. The partially methylated alditol acetates were analyzed on an Agilent 7890A GC interfaced to a 5975C MSD (mass selective detector, electron impact ionization mode). Separation was performed on Supelco 2331 fused-silica capillary column $(30 \mathrm{~m} \times 0.25 \mathrm{~mm}$ ID; Sigma-Aldrich $)$.

\section{NMR Spectroscopy}

The NMR spectra for the samples were collected at $25^{\circ} \mathrm{C}$ on a Varian Inova spectrometer $\left({ }^{1} \mathrm{H}, 600 \mathrm{MHz}\right.$; Varian Inc., Palo Alto, CA) equipped with a tripleresonance cold probe. Standard experiments present in the spectrometer library were used. Correlated spectroscopy (COSY) spectra were collected in a phasesensitive mode with a double-quantum filter. Total correlation spectroscopy (TOCSY) spectra were collected with mixing times of 30 and $80 \mathrm{~ms}$, and nuclear Overhauser effect spectroscopy (NOESY) spectra with mixing times of 70 and $200 \mathrm{~ms}$. Heteronuclear multiple bond correlation (HMBC) spectra were collected with a delay corresponding to a multi-bond coupling of 9 Hz. The NMR data were referenced to internal 4,4-dimethyl-4-silapentane-1-sulfonic acid (DSS), processed in NMRPipe (https://www.ibbr.umd.edu/nmrpipe/ index.html) and analyzed using Collaborative Computational Project for NMR (CCPN) Analysis (https:// www.ccpn.ac.uk).

\section{RESULTS AND DISCUSSION}

\section{Purification of EPS and MW Determination}

The yield of EPS produced by $S$. thermophilus ASCC 1275 was $234 \pm 4.3 \mathrm{mg} / \mathrm{L}$ of culture medium and the EPS content was $163 \pm 5.6 \mathrm{mg}$ of D-glucose equivalents/L of culture medium. The total carbohydrate content, protein content, and phenolics content of EPS produced by S. thermophilus ASCC 1275 were previously reported by our group (Li and Shah, 2014, 2017). The EPS extracted from S. thermophilus ASCC 1275 were fractionated using a Superose 6 column, which has a larger separation range for polysaccharides (5-700 kDa) and the resolution improved considerably compared with a Superose 12 column, in terms of separation of high-MW peaks from lower MW peaks. A baseline drift was observed in the chromatogram, most likely due to the nature of the sample (Figure 1). This type of drift is often observed in very complex samples that contain several oligosaccharides with similar structure but different size that cannot be separated and reach the detector at very similar elution times.

As shown in Figure 1, 3 distinct peaks were observed, indicating that the sample consisted of 3 main components, with high, intermediate, and low MW (Table 1). The size of the high-MW component-fraction $(\mathbf{F}) 1-$ was not estimated accurately, because it was larger 


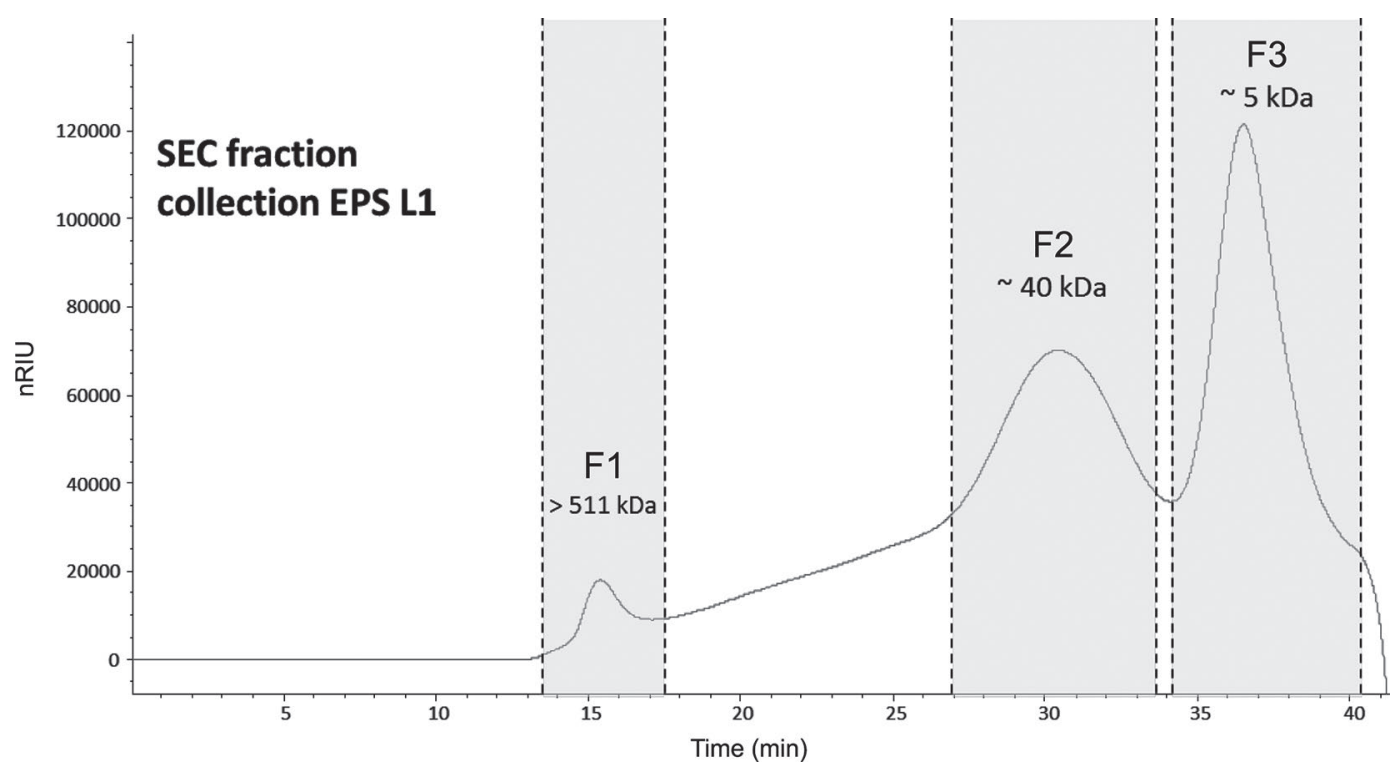

Figure 1. Size exclusion chromatogram (SEC) of Streptococcus thermophilus ASCC 1275 exopolysaccharide (EPS) on Superose 6 column (Cytiva/Global Life Sciences Solutions, Marlborough, MA). Gray areas represent fractions that were collected. The y-axis of the chromatogram is represented in nano-refractive index units (nRIU).

than the upper separation limit of the column used. The maximum MW of polysaccharides that can be estimated on this column is approximately $700 \mathrm{kDa}$; thus, any polysaccharide migrating in the void volume will have a MW of $\sim 700 \mathrm{kDa}$ or greater. However, because the highest MW standard analyzed was $511 \mathrm{kDa}$, we can only say with certainty that the high-MW component of the sample was $>511 \mathrm{kDa}$. The component with intermediate MW (F2) had an approximate size of $\sim 40$ $\mathrm{kDa}$, possibly corresponding to a small polysaccharide. These 2 fractions agree with the MW range of exopolysaccharide, $10^{4}$ to $10^{6} \mathrm{Da}$, observed in LAB (Patel et al., 2012; Sanalibaba and Cakmak, 2016). Finally, the main component of F3 corresponded to low-MW material, having an approximate MW of $\sim 5 \mathrm{kDa}$. Low-MW succinoglycans were found to be produced by various soil bacteria including Rhizobium, Agrobacterium, Alcaligenes, and Pseudomonas (Rinaudi and González, 2009; Freitas et al., 2011). However, no reports have reported low-MW EPS fractions from LAB.

\section{Monosaccharide Composition}

For glycosyl composition analysis, fractions were collected every minute and pooled according to Figure 1. Once freeze-dried and free of buffer residues, the collected fractions were used for glycosyl composition analysis. The amounts of monosaccharides found in the collected fractions by trimethylsilyl (TMS) glycosyl composition analysis, and the overall carbohydrate contents of each fraction are shown in Table 2 .
A comparative overlay of the total ion current (TIC) chromatograms from each fraction is shown in Figure 2 . Results suggest that the collected fractions corresponded to different polysaccharides. Although all fractions contained glucose, galactose, and mannose, the ratio of monosaccharides changed considerably among fractions (Table 2). In F1 and F3, the amount of glucose was higher (F1: 80.4\%; F3: 41.7\%) followed by galactose (F1: 11.0\%; F3: 23.9\%) and mannose (F1: 8.6\%; F3: 12.0\%). A study conducted on the biodiversity of exopolysaccharides produced by 26 strains of $S$. thermophilus reported glucose and galactose as the major monomers present in the EPS (Vaningelgem et al., 2004). Pachekrepapol et al. (2017) also reported glucose and galactose as the major components of EPS isolated from $6 S$. thermophilus strains. However, in F2 collected from $S$. thermophilus ASCC 1275 EPS, mannose $(61.7 \%)$ was the main component (Table 2 ). In addition to these monosaccharides, ribose $(22.4 \%)$ was

Table 1. Molecular weights (MW) and peak area percentages of Streptococcus thermophilus ASCC 1275 exopolysaccharide separated using Superose 6 column (Cytiva/Global Life Sciences Solutions, Marlborough, MA)

\begin{tabular}{lcc}
\hline Peak & $\begin{array}{c}\text { Approximate } \\
\text { MW (kDa) }\end{array}$ & $\begin{array}{c}\text { Relative peak } \\
\text { area (\%) }\end{array}$ \\
\hline 1 & $>511$ & 2.6 \\
2 & 40 & 45.8 \\
3 & 5 & 51.6 \\
\hline
\end{tabular}


Table 2. Glycosyl composition analysis results of Streptococcus thermophilus ASCC 1275 exopolysaccharide

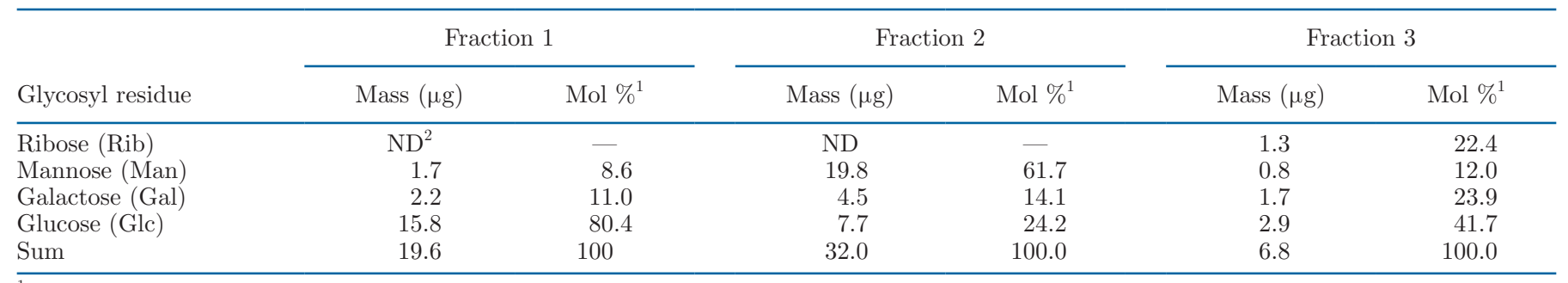

${ }^{1}$ Values are expressed as mole percent of total carbohydrates.

${ }^{2} \mathrm{ND}=$ not detected.

detected in F3, suggesting the presence of nucleic acid. Because of the small amount of material collected from F1, it was difficult to determine the accurate weight without sample loss. Hence, total percent carbohydrate for this fraction was not calculated. Only F2 and F3 were used for further analysis.

\section{Linkage Analysis}

Carbohydrate linkage analysis was performed for F2 and F3 to corroborate the structural analysis by NMR (Table 3, Figure 3). Major linkages present in F2 were 4-linked glucopyranosyl (4-Glc or 4-Glcp; $48 \mathrm{~mol} \%$ ), followed by terminal mannopyranosyl (tMan), 2- and 3-linked mannopyranosyl (2-Man/3Man) and 2,6-linked mannopyranosyl (2,6-Man; total $\sim 28 \mathrm{~mol} \%$ ). The mannose linkages identified in this study are consistent with the structure of mannans determined by NMR. However, polysaccharides that contain 4-linked glucose residues could not be identified by NMR. This type of inconsistency or underestimation of Glc was observed in insoluble polysaccharides due to the effects of premethylation on hydrolysis efficiency (Black et al., 2019). In F3, the major linkages present were terminal galactopyranosyl (t-Gal), 3-linked glucopyranosyl (3-Glc), 3-linked galactofuranosyl (3-Galf) and 3,6-linked glucopyranosyl (3,6-Glc; $12-18 \mathrm{~mol} \%)$, which agrees with the structure of the major polysaccharide in F3 as determined by NMR. Additionally, the presence of 6-linked glucopyranosyl (6-Glc) and 4-linked galactopyranosyl (4-gal) is consistent with the NMR structures of the 2 minor polysaccharides in F3. Previous reports showed that EPS produced by $S$. thermophilus is mainly composed of glucose and galactose; however, different monosaccharide combinations have been observed (Lemoine et al., 1997; de Vuyst et al., 2003; Zhang et al., 2016; Cui et al., 2017). Linkage patterns similar to that of $S$. thermophilus ASCC 1275 EPS have been observed in $S$. thermophilus Sfi20, $S$. thermophilus SY102, and S. thermophilus CH101 (Navarini et al., 2001; de Vuyst et al., 2003; Vaningelgem et al., 2004).

\section{Structure Determination by NMR}

The structures of polysaccharides present in F2 and F3 were determined based on the combination of 1- and 2-dimensional NMR methods (Figures 4 and 5). Initially, all ${ }^{1} \mathrm{H}$ and ${ }^{13} \mathrm{C}$ signals in the heteronuclear multiple quantum correlation (HSQC) spectrum were assigned to individual sugar residues by a combination of 2-dimensional COSY, TOCSY, HMBC (through-bond correlations), and NOESY (through-space correlation) experiments. A total of 7 sugar residues were identified in F2 in addition to those found in F3. The residues of F2 are labeled $\mathrm{K}$ to $\mathrm{P}$ in Table 4 and Figure 5. Because of numerous overlaps and overall weak signals, signals of only one residue $(\mathrm{O})$ were assigned fully; the other residues were only partly assigned. For residue K, only signals of the anomeric group were found. In Table 4, where the entries are missing, the correlation signals in 2-dimensional spectra confirming the shifts could not be identified. However, the existing assignments were sufficient to identify the residues shown in Table 4 . The shifts of mannans can be compared with those reported in Zarnowski et al. (2018).

The assignments of NMR signals of individual sugar residues were used to identify sugars based on the comparison of the chemical shifts with database values (Lundborg and Widmalm, 2011; Bock and Pedersen, 1983). Anomeric forms of the residues were determined based on characteristic ${ }^{1} \mathrm{H}$ and ${ }^{13} \mathrm{C}$ shifts of the anomeric groups as well as nuclear Overhauser effect (NOE) patterns. Linkages between sugars were determined based on intermolecular through-bond and through-space interactions between the linked positions. The linkage positions were also supported by the down-field chemical shift changes of the ${ }^{13} \mathrm{C}$ atoms closest to the linkage. The identified sugars and connections were consistent with chemical linkage analysis (Table 3 ).

\section{Residues L, M, N, N', O, P}

The residues $\mathrm{L}, \mathrm{M}, \mathrm{N}, \mathrm{N}$ ', $\mathrm{O}, \mathrm{P}$ were dominant in $\mathrm{F} 2$ and displayed similar chemical shifts. The pairs $\mathrm{N}$ and 
$\mathrm{N}^{\prime}$ as well as $\mathrm{O}$ and $\mathrm{P}$ were partly overlapping, suggesting similar but heterogeneous structural elements. All of these residues were identified as $\alpha$-D-mannopyranosyl $(\boldsymbol{\alpha}-\operatorname{Man} \boldsymbol{p})$ based on characteristic shifts and relatively strong NOE between H-1 and H-2 (Venisse et al., 1995). Residues $\mathrm{O}$ and $\mathrm{P}$ are terminal $\alpha-\operatorname{Man} p$ residues. The reducing end of residue $\mathrm{O}$ is connected to position 2 of residue $\mathrm{L}$ based on long-range $\mathrm{HMBC}$ correlations and NOE between $\mathrm{H}-1(\mathrm{O})$ and $\mathrm{H}-2(\mathrm{~L})$. Residue $\mathrm{L}$ is a 2 -linked $\alpha-\operatorname{Man} p$ residue with its reducing end linked to position 2 of residue $\mathrm{N}^{\prime}$ as indicated by HMBC and
NOE correlations. Based on the limited set of chemical shifts, residue N' appears to be a 2,6-linked $\alpha$-Man $p$ but we have not been able find NMR correlations confirming the 6-linkage. However, the presence of 2,6-Man residue was evident from the linkage analysis (Table 3 ).

The reducing end of residue $\mathrm{P}$ is connected to 2-position of residue $\mathrm{N}$ (HMBC and NOE correlations). Residue N, like residue N', appears to be a 2,6-linked $\alpha$-Man $p$ based on chemical shifts but the 6-linkage was not confirmed by NMR correlations. Residue $M$ was tentatively identified as a terminal $\alpha$-Man $p$ based on

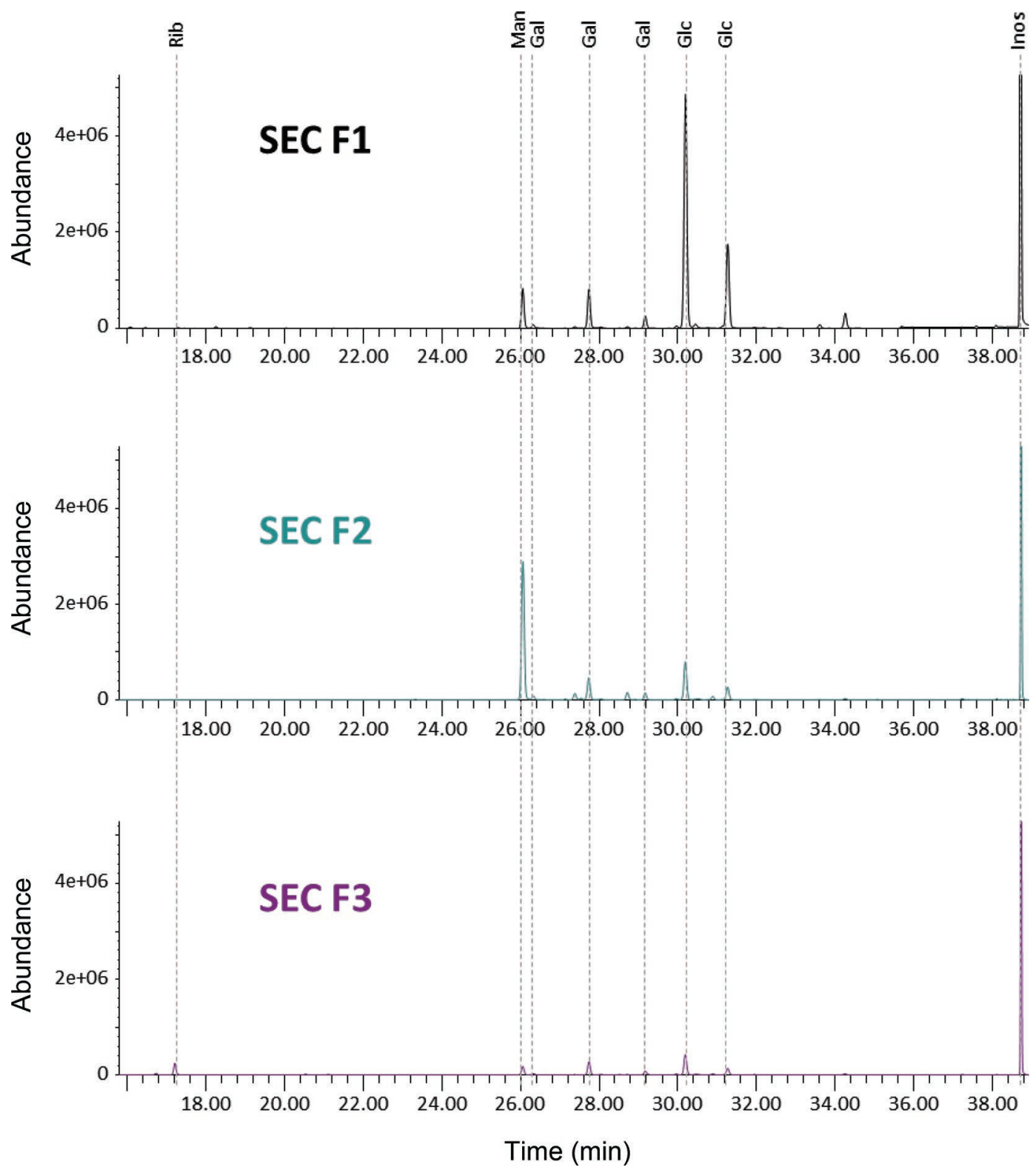

Figure 2. Comparative glycosyl composition analysis of fraction (F)1, F2, and F3 by size exclusion chromatography (SEC). Rib = ribose; Man = mannose; Gal = galactose; Glc = glucose; Inos = inositol (internal standard) 
Table 3. Relative percentages of linkages detected in fractions $(\mathrm{F})$ 2 and 3 of EPS produced by Streptococcus thermophilus ASCC 1275

\begin{tabular}{lrr}
\hline & \multicolumn{2}{c}{ Amount (mol\%) } \\
\cline { 2 - 3 } Residue & \multicolumn{1}{c}{$\mathrm{F} 2$} & \multicolumn{1}{c}{ F3 } \\
\hline Terminal mannopyranosyl (t-Man) & 9.2 & 4.2 \\
Terminal glucopyranosyl (t-Glc) & 6.7 & 6.4 \\
Terminal galactopyranosyl (t-Gal) & 1.8 & 11.8 \\
3-Linked glucopyranosyl (3-Glc) & 2.8 & 16.5 \\
2- + 3-Linked mannopyranosyl (2-Man + 3-Man) & 9.8 & 2.1 \\
3-Linked galactofuranosyl (3-Galf) & 3.2 & 17.6 \\
6-Linked galactopyranosyl (6-Gal) & 1.7 & 1.3 \\
6-Linked glucopyranosyl (6-Glc) & 1.6 & 6.0 \\
4-Linked galactopyranosyl (4-Gal) & 0.6 & 6.8 \\
4-Linked glucopyranosyl (4-Glc) & 48.2 & 5.7 \\
3,6-Linked glucopyranosyl (3,6-Glc) & 7.6 & 18.0 \\
2,6-Linked mannopyranosyl (2,6-Man) & 4.0 & 3.7 \\
4,6-Linked glucopyranosyl (4,6-Glc) & 100.0 & 100.0 \\
Sum & & \\
\hline
\end{tabular}

the similarity of available chemical shifts with residues $\mathrm{O}$ and $\mathrm{P}$. The linkage of residue $\mathrm{M}$ has not been found. Based on the available data, we hypothesize that fraction 2 contained mannans with structures as shown in Figure 6. A structurally similar mannan exopolysaccharide was produced by Lactobacillus crispatus L1 in semi-defined medium (Donnarumma et al., 2014). Two water-soluble mannan polysaccharides with MW 29 and $79 \mathrm{kDa}$ were isolated from the marine bacterium Edwardsiella tarda (Guo et al., 2010).

The NMR spectra contained additional signals indicating the presence of other polysaccharides, which would be consistent with the linkage analysis that showed the presence of additional 4- and 4,6-linked glucose residues in F2. The ${ }^{1} \mathrm{H}$ NMR data suggest that some of the sugars are acetylated but due to low in-

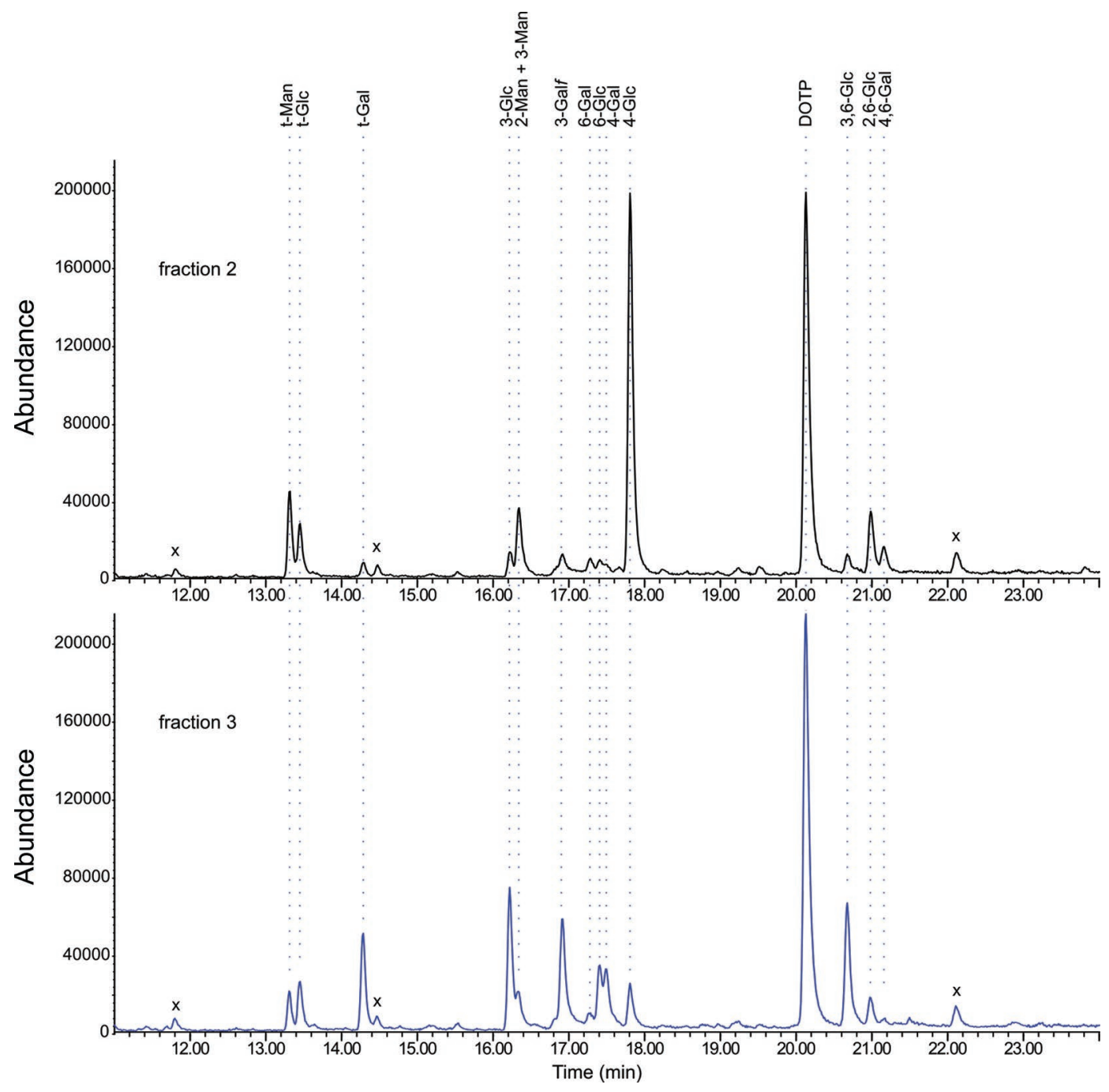

Figure 3. Gas chromatograms of partially methylated alditol acetates (PMAA) derivatives obtained for fractions 2 and 3. Peak assignments are indicated. DOTP $=$ dioctylterephthalate; $\mathrm{x}=$ unidentified compound. Refer to Table 3 for the full form of all the linkages mentioned in the chromatogram. 
Table 4. Assigned ${ }^{1} \mathrm{H}$ and ${ }^{13} \mathrm{C}$ nuclear magnetic resonance (NMR) chemical shifts of sugar residues found in fraction $2^{1}$

\begin{tabular}{|c|c|c|c|c|c|c|}
\hline \multirow[b]{2}{*}{ Residue $^{2}$} & \multicolumn{6}{|c|}{ Group } \\
\hline & 1 & 2 & 3 & 4 & 5 & 6 \\
\hline $\mathrm{K}$ & $\begin{array}{c}5.40 \\
102.5\end{array}$ & & & & & \\
\hline $\mathrm{L}$ & 5.30 & 4.12 & 3.92 & & 3.76 & \\
\hline 2)- $\alpha$-Man-(1- & 103.3 & 81.2 & 72.9 & & 76.1 & \\
\hline$M^{\prime}$ & 5.14 & 4.07 & 3.90 & & & \\
\hline t- $\alpha-M a n-(1-$ & 105.0 & $72.7 / 74.4$ & 73.1 & & & \\
\hline $\mathrm{N}$ & 5.12 & 4.04 & 3.93 & & 3.83 & \\
\hline 2,6)- $\alpha$-Man-(1- & 101.0 & 81.5 & 73.3 & & 73.9 & \\
\hline $\mathrm{N}^{\prime}$ & 5.10 & 4.03 & 3.92 & & 3.80 & \\
\hline 2,6)- $\alpha$-Man-(1- & 100.9 & 81.5 & 73.3 & & 74.0 & \\
\hline $\mathrm{O}$ & 5.06 & 4.07 & 3.84 & 3.64 & 3.77 & 3.90 \\
\hline t- $\alpha-M a n-(1-$ & 104.9 & 72.8 & 73.1 & 69.6 & 76.0 & 63.8 \\
\hline $\mathrm{P}$ & 5.05 & 4.08 & 3.81 & 3.67 & & \\
\hline t- $\alpha-\operatorname{Man}-(1-$ & 104.9 & 72.8 & 73.2 & 69.5 & & \\
\hline
\end{tabular}

${ }^{1}$ For each residue, the first row is the ${ }^{1} \mathrm{H}$ chemical shift and the second row is the ${ }^{13} \mathrm{C}$ shift.

$\left.{ }^{2} 2\right)$ - $\alpha$-Man-(1-: 2-linked or substituted $\alpha$-D-mannopyranosyl; t- $\alpha$-Man-(1-: terminal $\alpha$-D-mannopyranosyl; and 2,6)- $\alpha$-Man-(1-: 2,6-linked or substituted $\alpha$-D-mannopyranosyl.

tensity and overlaps of signals, we were not able to identify sugar constituents and deduce the structure of the unknown species.

In F3, a total of 6 major sugar residues were identified in the NMR spectra (labeled A-F in Table 5 and Figure 4). Residue A was assigned as a 3-linked glucopyranosyl based on similarity of its chemical shifts with published values and large down-field shift of C-3. Anomeric configuration was determined as $\alpha$ based on characteristic C-1, H-1, C-5 and H-5 shifts, small, unresolved H-1, $\mathrm{H}-2$ J-coupling, and strong NOE between $\mathrm{H}-1$ and $\mathrm{H}-2$. Strong NOE between $\mathrm{H}-1(\mathrm{~A})$ and $\mathrm{H}-3(\mathrm{C})$ as well as long-range $\mathrm{HMBC}$ correlations between respective groups indicated that the reducing end of residue $\mathrm{A}$ is linked to position 3 of residue $\mathrm{C}$.

Residue B was found to be in a furanose form based on HMBC correlations between groups 1 and 4. It was assigned as a 3-linked Galf based on similarity of its chemical shifts with published values (Bock and Pedersen, 1983), large down-field shift of C-3, and the results of linkage analysis. Anomeric configuration of residue $B$ was determined as $\beta$ based mainly on chemical shift similarity and small, unresolved $\mathrm{H}-1, \mathrm{H}-2$ J-coupling. Strong NOE between H-1(B) and H-3(A) as well as long-range $\mathrm{HMBC}$ correlations between respective groups indicated that the reducing end of residue $\mathrm{B}$ is linked to position 3 of residue $\mathrm{A}$. Residue $\mathrm{C}$ was assigned as a 3- and 6-linked Glc $p$ based on the similarity of its chemical shifts with published values and large downfield shifts of C-3 and C-6. Anomeric configuration was determined as $\beta$ based on characteristic $\mathrm{C}-1, \mathrm{H}-1, \mathrm{C}-5$ and $\mathrm{H}-5$ shifts, large $\mathrm{H}-1, \mathrm{H}-2$ J-coupling, and strong NOE between H-1, H-3 and H-5. Strong NOE between
$\mathrm{H}-1(\mathrm{C})$ and $\mathrm{H}-3(\mathrm{~B})$ as well as long-range HMBC correlations between respective groups indicated that reducing end of residue $\mathrm{C}$ is linked to position 3 of residue $\mathrm{B}$.

Residue $\mathrm{F}$ was assigned as a terminal galactopyranosyl (t-Gal or t-Galp) based on similarity of its chemical shifts with published values. Its anomeric configuration was determined as $\beta$ based on characteristic C-1, H-1, C-5, and H-5 shifts, large H-1, H-2 J-coupling, and strong NOEs between $\mathrm{H}-1, \mathrm{H}-3$, and $\mathrm{H}-5$. Strong NOE between $\mathrm{H}-1(\mathrm{~F})$ and $\mathrm{H}-6(\mathrm{C})$, as well as long-range $\mathrm{HMBC}$ correlations between respective groups indicated that the reducing end of residue $\mathrm{F}$ is linked to position 6 of residue C. Residues D and E were assigned as homopolymeric 4-linked Gal $p$ and 6-linked Glcp, respectively, based on similarity of their chemical shifts with published values and intra-residual HMBC correlations. The linkage of $\mathrm{D}$ was corroborated by NOE between H-1(D) and H-4(D) as well as a large down-field shift of C-4(D). Similarly, the linkage of E was corroborated by NOEs between $\mathrm{H}-1(\mathrm{E})$ and $\mathrm{H}-6(\mathrm{E})$ as well as large down-field shift of C-6(E). The anomeric configurations of $\mathrm{D}$ and $\mathrm{E}$ were determined as $\beta$ based on characteristic C-1, H-1, C-5, and H-5 shifts, large H-1, H-2 J-couplings, and strong NOE between $\mathrm{H}-1, \mathrm{H}-3$ and $\mathrm{H}-5$.

Based on the data, we identified 3 different polysaccharide structures, as shown in Figure 7. The EPS produced by $S$. thermophilus ASCC 1275 was found to be a branched heteropolysaccharide made of glucose and galactose residues. The linear chain consisted of $\alpha$-D-glucose, $\beta$-D-glucose, and $\alpha$-D-galactose linked by $(1 \rightarrow 3)$ linkages. Branching occurred at $\beta$-D-glucose, which connected $\beta$-D-galactose through $(1 \rightarrow 6)$ linkage. 
Exopolysaccharides with similar structure were reported to be produced by the strains DGCC 7710 and STCth-9204 in a study conducted for the characterization of EPS produced from different $S$. thermophilus strains (Pachekrepapol et al., 2017). However, the reason for the similarity in structure is unknown because complete genome information of these strains is unavailable. Exopolysaccharides with glucose and galactose residues are produced by $S$. thermophilus SFi39 (Lemoine et al., 1997) and S. thermophilus LY03 (Degeest and De Vuyst, 2000). Reports have shown that Lactococcus lactis ssp. cremoris NIZO B891 (Van Casteren et al., 2000), Lactococcus lactis ssp. cremoris Ropy 352
(Knoshaug et al., 2007), L. delbrueckii ssp. bulgaricus OLL 1073R-1 (Kitazawa et al., 2000), L. delbrueckii ssp. bulgaricus NCFB 2772 (Grobben et al., 1996), L. delbrueckii ssp. bulgaricus Lb18 (Petry et al., 2003), Lb. helveticus TN-4 (Yamamoto et al.,1995), Lb. helveticus 766 (Robijn et al., 1995), Lb. helveticus 2091 (Staaf et al., 1996), and Lb. helveticus Lb161 (Staaf et al., 2000) produced exopolysaccharide containing glucose and galactose residues. The NMR spectra contained additional minor signals that were not assigned. Those signals belonged in part to polysaccharides present mainly in F2, and in part to possible additional low-abundance polysaccharides or to terminal sugar residues.

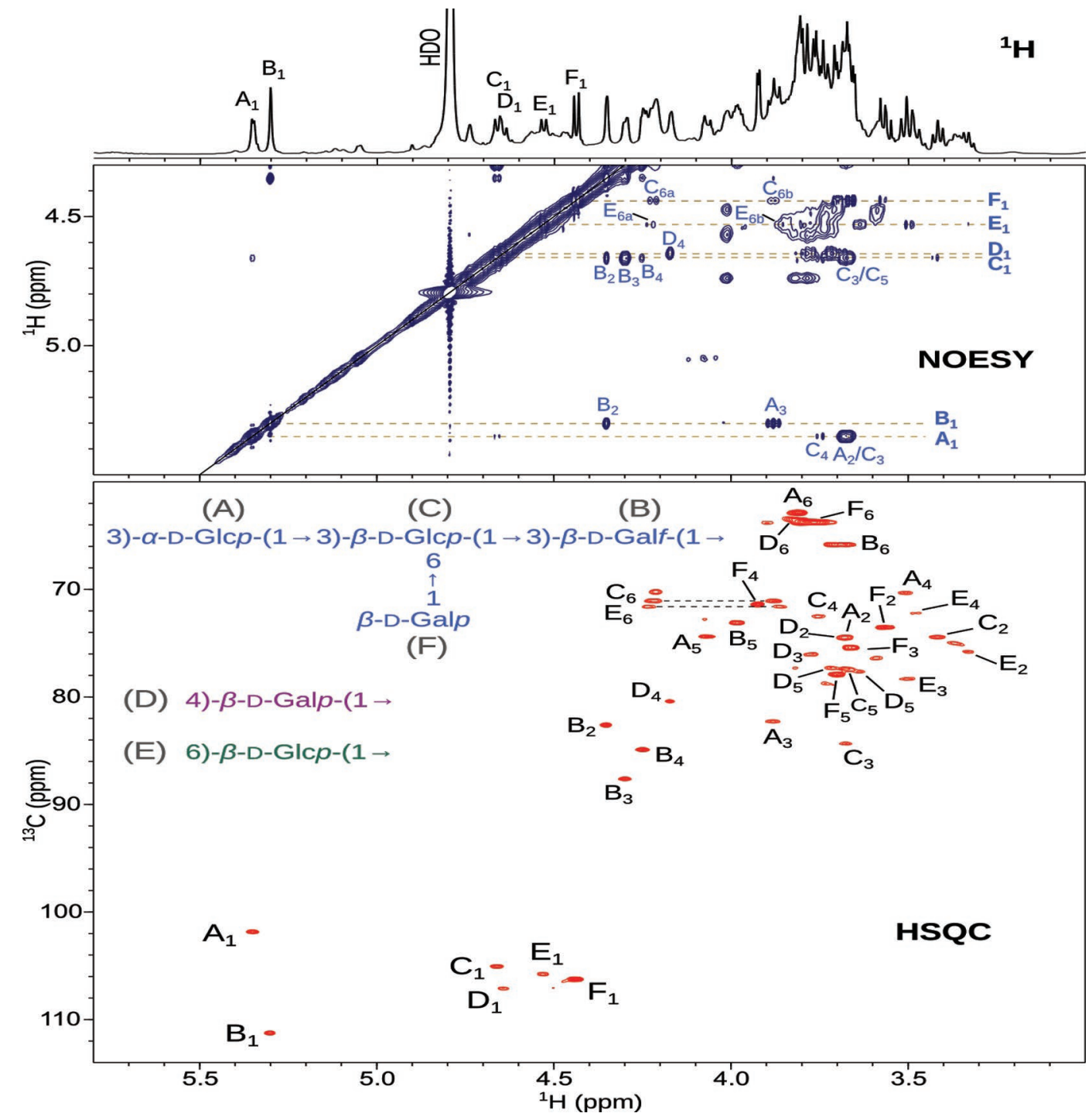

Figure 4. Carbohydrate regions of ${ }^{1} \mathrm{H}$, nuclear Overhauser effect spectroscopy (NOESY, $200 \mathrm{~ms}$ ), and ${ }^{1} \mathrm{H}-{ }^{13} \mathrm{C}$ heteronuclear multiple quantum correlation (HSQC) spectra of fraction 3. Signal assignments of major polysaccharides are indicated in the HSQC spectrum. Prominent intraand inter-residual interaction peaks are marked in the NOESY spectrum for anomeric ${ }^{1} \mathrm{H}$ resonances above or below the horizontal dashed lines. Each letter in the figure corresponds to the residues in Tables 4 and 5 . The number following the letter corresponds to the number of $\mathrm{C}-\mathrm{H}$ group within that residue. For example, $\mathrm{A}_{1}$ is the signal of the first anomeric $\mathrm{C}-\mathrm{H}$ group of residue $\mathrm{A}$. 


\section{CONCLUSIONS}

Streptococcus thermophilus ASCC 1275 was found to produce 2 types of exopolysaccharides. Glycosyl composition and linkage analysis coupled with 1 - and 2-dimensional NMR revealed the structure of these fractions. The major fraction (51.6\%) of EPS, with molecular weight of $5 \mathrm{kDa}$, was made of $\alpha$-D- glucopy- ranosyl, $\beta$-D-glucopyranosyl, and $\beta$-D-galactofuranosyl residues linked with $(1 \rightarrow 3)$ linkages in the linear chain and $(1 \rightarrow 6)$ linkages at branches. The second prominent fraction $(45.8 \%)$ comprised mannans linked by $(1 \rightarrow 2)$ linkages. Thus, we have identified the structure of $S$. thermophilus ASCC 1275 EPS, an EPS that improves the texture and rheological properties of various fermented foods.

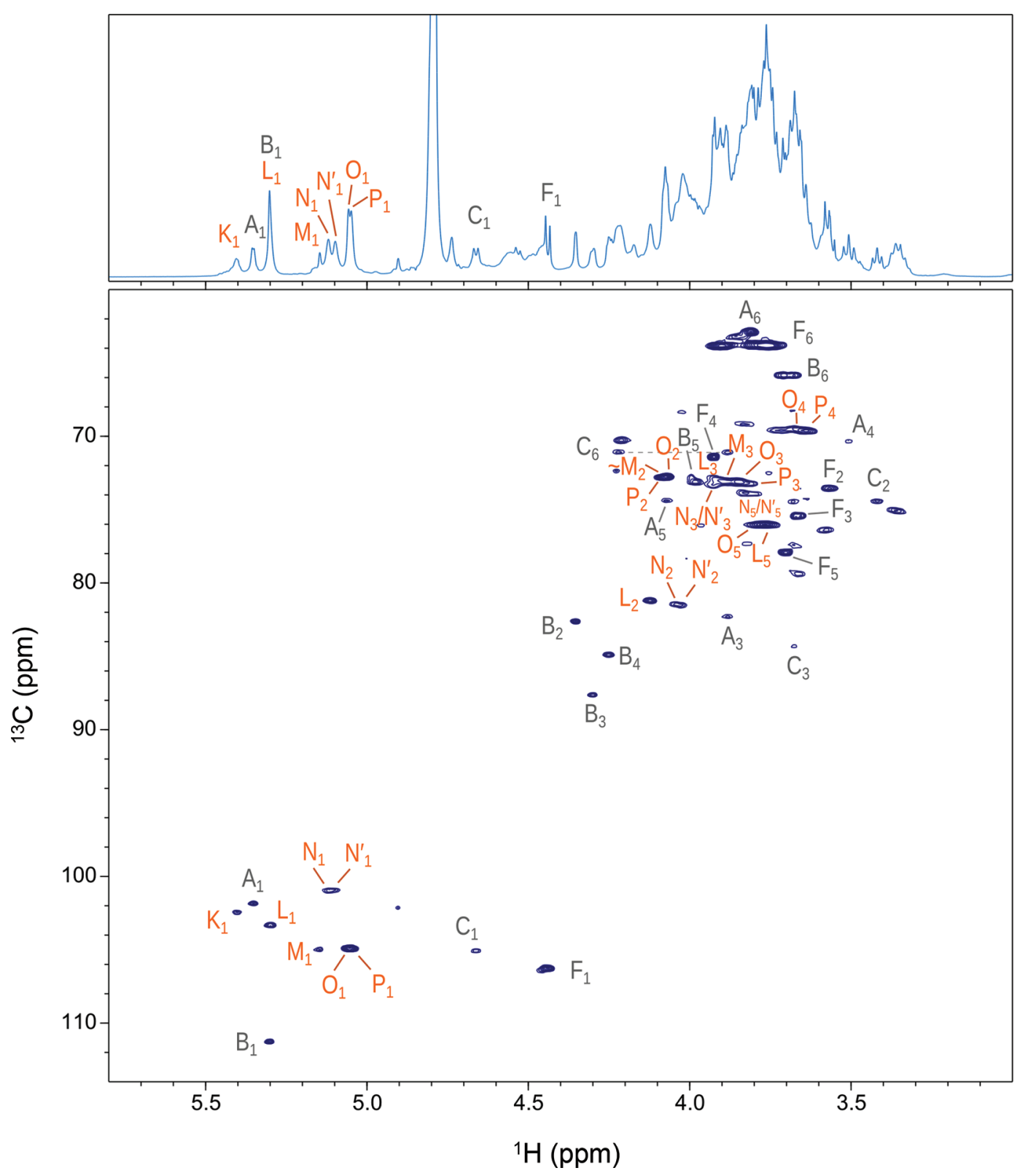

Figure 5. Carbohydrate regions of ${ }^{1} \mathrm{H}$ and ${ }^{1} \mathrm{H},{ }^{13} \mathrm{C}$ heteronuclear multiple quantum correlation (HSQC) spectra of fraction 2. Assignments of signals are indicated in orange for major polysaccharides of fraction 2, and in gray for polysaccharides that were dominant in fraction 3 . Each letter in the figure corresponds to the residues in Tables 4 and 5. The number following the letter corresponds to the number of $\mathrm{C}-\mathrm{H}$ group within that residue. For example, $\mathrm{A}_{1}$ is the signal of the first anomeric $\mathrm{C}-\mathrm{H}$ group of residue $\mathrm{A}$. 
Table 5. Assigned ${ }^{1} \mathrm{H}$ and ${ }^{13} \mathrm{C}$ nuclear magnetic resonance chemical shifts of sugar residues found in fraction $3^{1}$

\begin{tabular}{|c|c|c|c|c|c|c|}
\hline \multirow[b]{2}{*}{ Residue $^{2}$} & \multicolumn{6}{|c|}{ Group } \\
\hline & 1 & 2 & 3 & 4 & 5 & 6 \\
\hline $\mathrm{A}$ & 5.35 & 3.68 & 3.88 & 3.51 & 4.07 & 3.81 \\
\hline 3)- $\alpha$-Glc- $(1-$ & 101.9 & 74.5 & 82.3 & 70.3 & 74.4 & 62.9 \\
\hline B & 5.30 & 4.35 & 4.30 & 4.25 & 3.98 & $3.71,3.67$ \\
\hline 3)- $\beta$-Galf-(1- & 111.3 & 82.6 & 87.6 & 84.9 & 73.1 & 65.8 \\
\hline $\mathrm{C}$ & 4.66 & 3.41 & 3.67 & 3.76 & 3.68 & $4.22,3.88$ \\
\hline $\begin{array}{l}6 \\
\downarrow\end{array}$ & 105.1 & 74.4 & 84.3 & 72.5 & 77.4 & 71.1 \\
\hline $\begin{array}{l}\text { 3)- } \beta \text {-Glc- }(1- \\
\text { D }\end{array}$ & 464 & 268 & 378 & & & \\
\hline 4)- $\beta$-Gal-(1- & $\begin{array}{r}4.64 \\
107\end{array}$ & $\begin{array}{r}3.68 \\
74.5\end{array}$ & 3.78 & 4.17 & 3.72 & $\begin{array}{r}3.80 \\
635\end{array}$ \\
\hline $\mathrm{E}$ & 4.53 & 3.33 & 3.51 & $\begin{array}{c}0.4 \\
3.48\end{array}$ & 3.64 & $4.23,3.86$ \\
\hline 6$)-\beta-G l c-(1-$ & 105.8 & 75.8 & 78.3 & 72.2 & 77.7 & 71.6 \\
\hline $\mathrm{F}$ & 4.44 & 3.57 & 3.66 & 3.92 & 3.70 & $3.79,3.76$ \\
\hline t- $\beta$-Gal-(1- & 106.3 & 73.6 & 75.4 & 71.4 & 77.9 & 63.8 \\
\hline
\end{tabular}

${ }^{1}$ For each residue, the first row is the $1 \mathrm{H}$ chemical shift and the second row is $13 \mathrm{C}$ shift.

${ }^{2} 3$ )- $\alpha$-Glc-(1-: 3-linked or substituted $\alpha$-D-glucopyranosyl; 3)-3-Galf-(1-: 3-linked or substituted $\beta$-Dgalactofuranosyl; $6 \downarrow$ 3)- $\beta$-Glc-(1-: 3,6-linked or substituted $\beta$-D-galactopyranosyl; 4)- $\beta$-Gal-(1-: 4-linked or substituted $\beta$-D-galactopyranosyl; 6)- $\beta$-Glc-(1-: 6 -linked or substituted $\beta$-D-glucopyranosyl; and t- $\beta$-Gal-(1-: terminal $\beta$-D-galactopyranosyl.

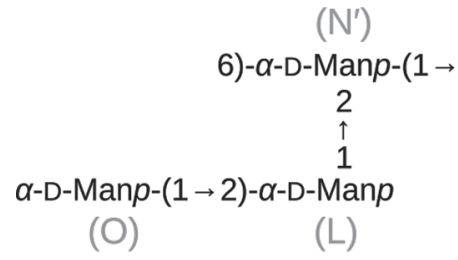

Structure 1

Figure 6. Structure of Streptococcus thermophilus ASCC 1275 exopolysaccharide (EPS) in fraction 2 . Structure 1 and structure 2 refer to the 2 polysaccharides identified in fraction 2 . All abbreviations used in this figure are defined in Tables 4 and 5.

(A) $\quad(C)$

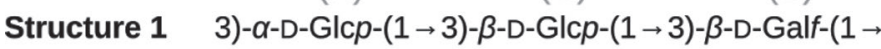

6
$\uparrow$-D-Galp
1

(D)

Structure 2 4)- $\beta$-D-Galp-(1 $\rightarrow$

(E)

\section{Structure 3 6)- $\beta$-D-Glcp-(1 $\rightarrow$}

Figure 7. Structure of Streptococcus thermophilus ASCC 1275 exopolysaccharide (EPS) in fraction 3. Structure 1, structure 2, and structure 3 refer to the 3 polysaccharides identified in fraction 3. All abbreviations used in this figure are defined in Tables 4 and 5 .

\section{ACKNOWLEDGMENTS}

This work is supported by General Research Fund (project code: 17105315) from Research Grants Council of University Grants Committee, Hong Kong. The authors acknowledge Parastoo Azadi and the Complex Carbohydrate Research Centre at the University of Georgia, Athens, for assistance with sample processing. We also thank Sara Linden, Christian Heiss, and Jiri Vlach (Carbohydrate Research Centre at the University of Georgia, Athens) for technical assistance. The authors have not stated any conflicts of interest.

\section{REFERENCES}

Ai, L., Q. Guo, H. Ding, B. Guo, W. Chen, and S. W. Cui. 2016. Structure characterization of exopolysaccharides from Lactobacillus casei LC2W from skim milk. Food Hydrocoll. 56:134-143. https:// doi.org/10.1016/j.foodhyd.2015.10.023.

Amatayakul, T., F. Sherkat, and N. P. Shah. 2006a. Physical characteristics of set yoghurt made with altered casein to whey protein ratios and EPS-producing starter cultures at 9 and $14 \%$ total solids. Food Hydrocoll. 20:314-324. https://doi.org/10.1016/j .foodhyd.2005.02.015.

Amatayakul, T., F. Sherkat, and N. P. Shah. 2006b. Syneresis in set yogurt as affected by EPS starter cultures and levels of solids. Int. J. Dairy Technol. 59:216-221. https://doi.org/10.1111/j.1471-0307 .2006.00264.x.

Bajpai, V. K., I. A. Rather, R. Majumder, S. Shukla, A. Aeron, K. Kim, S. C. Kang, R. Dubey, D. Maheshwari, J. Lim, and Y.-H. Park. 2015. Exopolysaccharide and lactic acid bacteria: Perception, functionality and prospects. Bangladesh J. Pharmacol. 11:123. https://doi.org/10.3329/bjp.v11i1.23819.

Bhaskaracharya, R., and N. P. Shah. 2000. Texture characteristics and microstructure of skim milk mozzarella cheeses made using exopolysaccharide or non-exopolysaccharide producing starter cultures. Aust. J. Dairy Technol. 55:132. 
Black, I., C. Heiss, and P. Azadi. 2019. Comprehensive monosaccharide composition analysis of insoluble polysaccharides by permethylation to produce methyl alditol derivatives for gas chromatography/mass spectrometry. Anal. Chem. 91:13787-13793. https://doi .org/10.1021/acs.analchem.9b03239.

Bock, K., and C. Pedersen. 1983. Carbon-13 nuclear magnetic resonance spectroscopy of monosaccharides. Adv. Carbohydr. Chem. 41:27-66. https://doi.org/10.1016/S0065-2318(08)60055-4.

Cui, Y., X. Jiang, M. Hao, X. Qu, and T. Hu. 2017. New advances in exopolysaccharides production of Streptococcus thermophilus. Arch. Microbiol. 199:799-809. https://doi.org/10.1007/s00203-017 -1366-1.

de Vuyst, L., F. De Vin, F. Vaningelgem, and B. Degeest. 2001. Recent developments in the biosynthesis and applications of heteropolysaccharides from lactic acid bacteria. Int. Dairy J. 11:687-707. https://doi.org/10.1016/S0958-6946(01)00114-5.

De Vuyst, L., M. Zamfir, F. Mozzi, T. Adriany, V. Marshall, B. Degeest, and F. Vaningelgem. 2003. Exopolysaccharide-producing Streptococcus thermophilus strains as functional starter cultures in the production of fermented milks. Int. Dairy J. 13:707-717. https: //doi.org/10.1016/S0958-6946(03)00105-5.

Degeest, B., and L. De Vuyst. 2000. Correlation of activities of the enzymes $\alpha$-phosphoglucomutase, UDP-galactose 4-epimerase, and UDP-glucose pyrophosphorylase with exopolysaccharide biosynthesis by Streptococcus thermophilus LY03. Appl. Environ. Microbiol. 66:3519-3527. https://doi.org/10.1128/AEM.66.8.3519-3527 .2000 .

Dimopoulou, M., M. Vuillemin, H. Campbell-Sills, P. M. Lucas, P. Ballestra, C. Miot-Sertier, M. Favier, J. Coulon, V. Moine, T. Doco, M. Roques, P. Williams, M. Petrel, E. Gontier, C. Moulis, M. Remaud-Simeon, and M. Dols-Lafargue. 2014. Exopolysaccharide (EPS) synthesis by Oenococcus oeni: From genes to phenotypes. PLoS One 9:e98898. https://doi.org/10.1371/journal.pone .0098898 .

Donnarumma, G., A. Molinaro, D. Cimini, C. De Castro, V. Valli, V. De Gregorio, M. De Rosa, and C. Schiraldi. 2014. Lactobacillus crispatus L1: High cell density cultivation and exopolysaccharide structure characterization to highlight potentially beneficial effects against vaginal pathogens. BMC Microbiol. 14:137. https://doi .org/10.1186/1471-2180-14-137.

DuBois, M., K. A. Gilles, J. K. Hamilton, P. A. Rebers, and F. Smith. 1956. P. A. Colorimetric method for determination of sugars and related substances. Anal. Chem. 28:350-356. https://doi.org/10 .1021/ac60111a017.

Freitas, F., V. D. Alves, and M. A. Reis. 2011. Advances in bacterial exopolysaccharides: from production to biotechnological applications. Trends Biotechnol. 29:388-398. https://doi.org/10.1016/j .tibtech.2011.03.008.

Grobben, G. J., M. R. Smith, J. Sikkema, and J. A. M. de Bont. 1996. Influence of fructose and glucose on the production of exopolysaccharides and the activities of enzymes involved in the sugar metabolism and the synthesis of sugar nucleotides in Lactobacillus delbrueckii ssp. bulgaricus NCFB 2772. Appl. Microbiol. Biotechnol. 46:279-284. https://doi.org/10.1007/s002530050817.

Guo, S., W. Mao, Y. Han, X. Zhang, C. Yang, Y. Chen, Y. Chen, J. Xu, H. Li, X. Qi, and J. Xu. 2010. Structural characteristics and antioxidant activities of the extracellular polysaccharides produced by marine bacterium Edwardsiella tarda. Bioresour. Technol. 101:4729-4732. https://doi.org/10.1016/j.biortech.2010.01.125.

Heiss, C., J. S. Klutts, Z. Wang, T. L. Doering, and P. Azadi. 2009. The structure of Cryptococcus neoformans galactoxylomannan contains $\beta$-D-glucuronic acid. Carbohydr. Res. 344:915-920. https:// doi.org/10.1016/j.carres.2009.03.003.

Ibarburu, I., A. I. Puertas, I. Berregi, M. A. Rodríguez-Carvajal, A. Prieto, and M. T. Dueñas. 2015. Production and partial characterization of exopolysaccharides produced by two Lactobacillus suebicus strains isolated from cider. Int. J. Food Microbiol. 214:54-62. https://doi.org/10.1016/j.ijfoodmicro.2015.07.012.

Khalil, E. S., M. Abd Manap, S. Mustafa, A. Alhelli, and P. Shokryazdan. 2018. Probiotic properties of exopolysaccharide-producing
Lactobacillus strains isolated from Tempoyak. Molecules 23:398. https://doi.org/10.3390/molecules23020398.

Kitazawa, H., Y. Ishii, J. Uemura, Y. Kawai, T. Saito, T. Kaneko, K. Noda, and T. Itoh. 2000. Augmentation of macrophage functions by an extracellular phosphopolysaccharide from Lactobacillus delbrueckii ssp. bulgaricus. Food Microbiol. 17:109-118. https://doi .org/10.1006/fmic.1999.0294.

Knoshaug, E. P., J. A. Ahlgren, and J. E. Trempy. 2007. Exopolysaccharide expression in Lactococcus lactis ssp. cremoris Ropy352: Evidence for novel gene organization. Appl. Environ. Microbiol. 73:897-905. https://doi.org/10.1128/AEM.01945-06.

Korcz, E., Z. Kerényi, and L. Varga. 2018. Dietary fibers, prebiotics, and exopolysaccharides produced by lactic acid bacteria: Potential health benefits with special regard to cholesterol-lowering effects. Food Funct. 9:3057-3068. https://doi.org/10.1039/c8fo00118a.

Laiño, J., J. Villena, P. Kanmani, and H. Kitazawa. 2016. Immunoregulatory effects triggered by lactic acid bacteria exopolysaccharides: New insights into molecular interactions with host cells. Microorganisms 4:27. https://doi.org/10.3390/microorganisms4030027.

Laws, A., Y. Gu, and V. Marshall. 2001. Biosynthesis, characterisation, and design of bacterial exopolysaccharides from lactic acid bacteria. Biotechnol. Adv. 19:597-625. https://doi.org/10.1016/ s0734-9750(01)00084-2.

Lemoine, J., F. Chirat, J.-M. Wieruszeski, G. Strecker, N. Favre, and J.-R. Neeser. 1997. Structural characterization of the exocellular polysaccharides produced by Streptococcus thermophilus SFi39 and SFi12. Appl. Environ. Microbiol. 63:3512-3518. https://doi.org/10 .1128/AEM.63.9.3512-3518.1997.

Li, S., R. Huang, N. P. Shah, X. Tao, Y. Xiong, and H. Wei. 2014 Antioxidant and antibacterial activities of exopolysaccharides from Bifidobacterium bifidum WBIN03 and Lactobacillus plantarum R315. J. Dairy Sci. 97:7334-7343. https://doi.org/10.3168/ jds.2014-7912.

Li, S., and N. P. Shah. 2014. Antioxidant and antibacterial activities of sulphated polysaccharides from Pleurotus eryngii and Streptococcus thermophilus ASCC 1275. Food Chem. 165:262-270. https:// doi.org/10.1016/j.foodchem.2014.05.110.

Li, S., and N. P. Shah. 2016. Characterization, anti-inflammatory and anti-proliferative activities of natural and sulfonated exo-polysaccharides from Streptococcus thermophilus ASCC 1275. J. Food Sci. 81:M1167-M1176. https://doi.org/10.1111/1750-3841.13276.

Li, S., and N. P. Shah. 2017. Sulphonated modification of polysaccharides from Pleurotus eryngii and Streptococcus thermophilus ASCC 1275 and antioxidant activities investigation using CCD and Caco2 cell line models. Food Chem. 225:246-257. https://doi.org/10 .1016/j.foodchem.2017.01.037.

Lundborg, M., and G. R. Widmalm. 2011. Structural analysis of glycans by NMR chemical shift prediction. Anal. Chem. 83:15141517. https://doi.org/10.1021/ac1032534.

Moscovici, M. 2015. Present and future medical applications of microbial exopolysaccharides. Front. Microbiol. 6:1012. https://doi.org/ 10.3389/fmicb.2015.01012.

Navarini, L., A. Abatangelo, C. Bertocchi, E. Conti, M. Bosco, and F. Picotti. 2001. Isolation and characterization of the exopolysaccharide produced by Streptococcus thermophilus SFi20. Int. J. Biol. Macromol. 28:219-226. https://doi.org/10.1016/S0141 -8130(01)00118-0.

Oleksy, M., and E. Klewicka. 2018. Exopolysaccharides produced by Lactobacillus sp.: Biosynthesis and applications. Crit. Rev. Food Sci. Nutr. 58:450-462. https://doi.org/10.1080/10408398.2016 .1187112 .

Pachekrepapol, U., J. Lucey, Y. Gong, R. Naran, and P. Azadi. 2017. Characterization of the chemical structures and physical properties of exopolysaccharides produced by various Streptococcus thermophilus strains. J. Dairy Sci. 100:3424-3435. https://doi.org/10 .3168/jds.2016-12125.

Patel, S., A. Majumder, and A. Goyal. 2012. Potentials of exopolysaccharides from lactic acid bacteria. Indian J. Microbiol. 52:3-12. https://doi.org/10.1007/s12088-011-0148-8. 
Patten, D. A., and A. P. Laws. 2015. Lactobacillus-produced exopolysaccharides and their potential health benefits: a review. Benef. Microbes 6:457-471. https://doi.org/10.3920/BM2014.0117.

Petry, S., S. Furlan, E. Waghorne, L. Saulnier, J. Cerning, and E. Maguin. 2003. Comparison of the thickening properties of four Lactobacillus delbrueckii ssp. bulgaricus strains and physicochemical characterization of their exopolysaccharides. FEMS Microbiol. Lett. 221:285-291. https://doi.org/10.1016/S0378-1097(03)00214 $-3$.

Purohit, D. H., A. Hassan, E. Bhatia, X. Zhang, and C. Dwivedi. 2009. Rheological, sensorial, and chemopreventive properties of milk fermented with exopolysaccharide-producing lactic cultures. J. Dairy Sci. 92:847-856. https://doi.org/10.3168/jds.2008-1256.

Purwandari, U., N. P. Shah, and T. Vasiljevic. 2007. Effects of exopolysaccharide-producing strains of Streptococcus thermophilus on technological and rheological properties of set-type yoghurt. Int. Dairy J. 17:1344-1352. https://doi.org/10.1016/j.idairyj.2007.01 .018 .

Rinaudi, L. V., and J. E. González. 2009. The low-molecular-weight fraction of exopolysaccharide II from Sinorhizobium meliloti is a crucial determinant of biofilm formation. J. Bacteriol. 191:72167224. https://doi.org/10.1128/JB.01063-09.

Robijn, G. W., J. R. Thomas, H. Haas, D. J. C. van den Berg, J. P. Kamerling, and J. F. G. Vliegenthart. 1995. The structure of the exopolysaccharide produced by Lactobacillus helveticus 766 . Carbohydr. Res. 276:137-154. https://doi.org/10.1016/0008 -6215(95)00171-o.

Sanalibaba, P., and G. A. Çakmak. 2016. Exopolysaccharides production by lactic acid bacteria. Appl. Microbiol. 2:115. https://doi .org/10.4172/2471-9315.1000115.

Santander, J., T. Martin, A. Loh, C. Pohlenz, D. M. Gatlin III, and R. Curtiss III.. 2013. Mechanisms of intrinsic resistance to antimicrobial peptides of Edwardsiella ictaluri and its influence on fish gut inflammation and virulence. Microbiology 159:1471-1486. https:// doi.org/10.1099/mic.0.066639-0.

Staaf, M., G. Widmalm, Z. Yang, and E. Huttunen. 1996. Structural elucidation of an extracellular polysaccharide produced by Lactobacillus helveticus. Carbohydr. Res. 291:155-164. https://doi.org/ 10.1016/S0008-6215(96)00166-8.

Staaf, M., Z. Yang, E. Huttunen, and G. Widmalm. 2000. Structural elucidation of the viscous exopolysaccharide produced by Lactobacillus helveticus Lb161. Carbohydr. Res. 326:113-119. https://doi .org/10.1016/S0008-6215(00)00027-6.

Torino, M. I., G. Font de Valdez, and F. Mozzi. 2015. Biopolymers from lactic acid bacteria. Novel applications in foods and beverages. Front. Microbiol. 6:834. https://doi.org/10.3389/fmicb.2015 .00834 .

van Casteren, W. H. M., P. de Waard, C. Dijkema, H. A. Schols, and A. G. J. Voragen. 2000. Structural characterization and enzymic modification of the exopolysaccharide produced by Lactococcus lactis ssp. cremoris B891. Carbohydr. Res. 327:411-422. https:// doi.org/10.1016/S0008-6215(00)00065-3.

Vaningelgem, F., M. Zamfir, F. Mozzi, T. Adriany, M. Vancanneyt, J. Swings, and L. De Vuyst. 2004. Biodiversity of exopolysaccharides produced by Streptococcus thermophilus strains is reflected in their production and their molecular and functional characteristics. Appl. Environ. Microbiol. 70:900-912. https://doi.org/10.1128/ AEM.70.2.900-912.2004.

Venisse, A., M. Rivière, J. Vercauteren, and G. Puzo. 1995. Structural analysis of the mannan region of lipoarabinomannan from $\mathrm{Myco-}$ bacterium bovis BCG. Heterogeneity in phosphorylation state. J. Biol. Chem. 270:15012-15021. https://doi.org/10.1074/jbc.270.25 .15012 .

Welman, A. D., and I. S. Maddox. 2003. Exopolysaccharides from lactic acid bacteria: Perspectives and challenges. Trends Biotechnol. 21:269-274. https://doi.org/10.1016/S0167-7799(03)00107-0.

Wu, Q., H. M. Tun, F. C.-C. Leung, and N. P. Shah. 2015. Genomic insights into high exopolysaccharide-producing dairy starter bacterium Streptococcus thermophilus ASCC 1275. Sci. Rep. 4:4974. https://doi.org/10.1038/srep04974.

Yamamoto, Y., T. Nunome, R. Yamauchi, K. Kato, and Y. Sone. 1995. Structure of an exocellular polysaccharide of Lactobacillus helveticus $\mathrm{TN}-4$, a spontaneous mutant strain of Lactobacillus helveticus TY1-2. Carbohydr. Res. 275:319-332. https://doi.org/10.1016/ 0008-6215(95)00077-7.

Zannini, E., D. M. Waters, A. Coffey, and E. K. Arendt. 2016. Production, properties, and industrial food application of lactic acid bacteria-derived exopolysaccharides. Appl. Microbiol. Biotechnol. 100:1121-1135. https://doi.org/10.1007/s00253-015-7172-2.

Zarnowski, R., H. Sanchez, A. S. Covelli, E. Dominguez, A. Jaromin, J. Bernhardt, K. F. Mitchell, C. Heiss, P. Azadi, A. Mitchell, and D. R. Andes. 2018. Candida albicans biofilm-induced vesicles confer drug resistance through matrix biogenesis. PLoS Biol. 16:e2006872. https://doi.org/10.1371/journal.pbio.2006872.

Zeidan, A. A., V. K. Poulsen, T. Janzen, P. Buldo, P. M. Derkx, G. Øregaard, and A. R. Neves. 2017. Polysaccharide production by lactic acid bacteria: From genes to industrial applications. FEMS Microbiol. Rev. 41(Supp_1):S168-S200. https://doi.org/10.1093/ femsre/fux017.

Zhang, J., Y. Cao, J. Wang, X. Guo, Y. Zheng, W. Zhao, X. Mei, T. Guo, and Z. Yang. 2016. Physicochemical characteristics and bioactivities of the exopolysaccharide and its sulphated polymer from Streptococcus thermophilus GST-6. Carbohydr. Polym. 146:368375. https://doi.org/10.1016/j.carbpol.2016.03.063.

Zisu, B., and N. P. Shah. 2003. Effects of pH, temperature, supplementation with whey protein concentrate, and adjunct cultures on the production of exopolysaccharides by Streptococcus thermophilus 1275. J. Dairy Sci. 86:3405-3415. https://doi.org/10.3168/jds .S0022-0302(03)73944-7.

Zisu, B., and N. P. Shah. 2005. Low-fat mozzarella as influenced by microbial exopolysaccharides, preacidification, and whey protein concentrate. J. Dairy Sci. 88:1973-1985. https://doi.org/10.3168/ jds.S0022-0302(05)72873-3.

\section{ORCIDS}

Aparna Padmanabhan ( https://orcid.org/0000-0001-5292-4350 Nagendra P. Shah @ https://orcid.org/0000-0003-4746-3232 